\title{
PRONOMES PESSOAIS DA LÍNGUA JAPONESA MODERNA: UM PANORAMA DAS TEORIAS CLÁSSICAS
}

\section{Wataru Kikuchi}

RESUMO: Por longo tempo, os pronomes pessoais da língua japonesa têm sido considerados um tópico difícil por aprendizes estrangeiros. Sendo assim, o objetivo deste artigo é contribuir para elucidar essa classe de palavras. Para tanto, são sintetizadas as principais abordagens de teóricos que estudaram os pronomes pessoais, focalizando os autores como Yamada Yoshio, Matsushita Daizaburô e Tokieda Motoki.

ABSTRACT: Japanese personal pronouns have been considered a difficult subject by foreigner apprentices for quite some time. So, this being the case, this article intends to contribute to elucidate this class of words. For that purpose, the essential approaches of theorists who have studied the personal pronouns are summarized, focusing on authors like Yamada Yoshio, Matsushita Daizaburô and Tokieda Motoki.

PALAVRAS-CHAVE: pronomes pessoais da língua japonesa, Yamada Yoshio, Tokieda Motoki, Matsushita Daizaburô.

KEYWORDS: Japanese personal pronouns, Yamada Yoshio, Tokieda Motoki, Matsushita Daizaburô. 


\section{1- Introdução}

Uma característica marcante dos pronomes pessoais da língua japonesa é a existência de uma profusão de variantes para cada pessoa. Assim, há várias versões correspondentes em japonês para o pronome que indica uma determinada pessoa no português, como "eu", "tu", e assim sucessivamente para todas as pessoas. Dessa forma, um aprendiz que resolve realizar uma consulta rápida nos principais dicionários português-japonês, disponíveis no Brasil, encontrará: watashi e watakushi para "eu", anata, omae e kimi para "tu", kare e anohito para "ele", watashitachi para "nós" e anatagata para "vós" 1 Mais adiante irá constatar que, embora não constem nos dicionários consultados, existem watashira e watakushidomo para "nós" e anatatachi para "vocês", entre outros, ou seja, que, na realidade, existem outras variantes, desconsiderando-se as variações dialetais e os casos da língua clássica, que se apresentam fora do foco do presente trabalho.

Embora esse detalhe já cause espanto e certa dificuldade no aprendiz, é necessário observar ainda o fato de que as versões citadas não podem ser consideradas substituíveis entre si em qualquer contexto, ou seja, do ponto de vista pragmáticodiscursivo, os pronomes da língua japonesa não podem ser resumidos a simples correlação acima apresentada. Torna-se necessário, assim, um estudo de envergadura e de uma sistematização que possa apresentar com maior propriedade o quadro de pronomes pessoais do japonês, sem cair na simplificação, ou na teorização excessiva, que seria muito pouco útil do ponto de vista didático.

O objetivo desse artigo é, pois, constituir a primeira parte de um estudo que, ampliando o quadro acima e apresentando outros pronomes pessoais da língua japonesa moderna ${ }^{2}$, contribuir para maior compreensão das propriedades dessa classe de palavras,via revisão teórica dos principais gramáticos japoneses.

\section{2- Posição dos autores clássicos}

Como classe de palavras, os pronomes pessoais da língua japonesa, jindaimeishi ou ninshôdaimeishi, fazem parte dos daimeishi, "pronomes", ao lado dos shijidaimeishi, "pronomes demonstrativos" ${ }^{3}$ Embora o objetivo deste trabalho não seja tratar a classe dos daimeishi como um todo, alguma referência será necessária, uma vez que a maio-

Pesquisado em Michaelis: Dicionário Prático Português-Japonês e Gendai Porutogarugo Jiten (Dicionário do Português Contemporâneo).

2 É necessário ponderar, entretanto, que ao longo do texto serão incluídos os pronomes atualmente considerados arcaicos, mas que foram citados pelos lingüistas aqui tratados.

3 Alguns estudiosos classificam um terceiro tipo, saikidaimeishi ou hanshadaimeishi, "pronomes reflexivos”, como jibun, jiko, jishin e jitai. Ver, por exemplo, KASHIWADANI, 1984. 
ria das peculiaridades dos jindaimeishi trata-se, na realidade, de características próprias dos pronomes da língua japonesa.

\section{1 - Fase de influência da gramática ocidental: João Rodriguez a Ôtsuki Fumihiko}

É possivel afirmar que a gramática japonesa, tal qual entendemos hoje, surge no Japão na esteira do contato com o Ocidente, sobretudo com os portugueses a partir do século XVI. Até então, os estudos sobre a língua japonesa enfocavam a estilística literária ou se tratavam de estudo lexical dos poemas waka. Embora seja possível identificar alguns estudos de natureza gramatical, sobretudo de classificação morfológica ${ }^{4}$, estes tinham outro propósito, o de aperfeiçoar a técnica poética (KOIKE, 1995: 198). É possível, ainda, encontrar alguma tentativa de sistematização gramatical nos estudos pioneiros de Fujitani Nariakira (1738-79) e de seu contemporâneo Motoori Norinaga (1730-1801), dentre outros, que realizaram vários estudos originais e importantes, sem, no entanto, chegar a uma abrangência ou perfeição da gramática ocidental $^{5}$.

Dessa forma, não seria espantoso que a primeira gramática da língua japonesa nos moldes da concepção ocidental tenha sido obra do estrangeiro João Rodriguez (1561? - 1634), que, entre 1604 e 1608, publicou em português a famosa obra Arte da Lingoa de Iapam ${ }^{6}$ Nesse trabalho, Rodriguez identifica o pronome como uma das dez classes de palavras, ao lado de Nome, Verbo, entre outras (SHIMA, 1969:124). Seu trabalho tem o mérito de ter realizado a primeira sistematização em termos de classes de palavras. Não obstante, teve pouca influência nos gramáticos japoneses posteriores, principalmente porque foi elaborado com o propósito de instruir os missionários portugueses (NISHIDA, 1984: 101). Cerca de trinta anos após Rodriguez, Didaco Collado publica Ars Grammaticae Iaponicae Linguae, em latim, no ano de 1632, em Roma. Collado assume, no prefácio dessa obra, ter se baseado largamente em Rodriguez (MATSUMURA, 1973: 10) ${ }^{7}$

Tendo como mais representativo o trabalho de Rodriguez, os estudos dessa fase que abrangeu a segunda metade do século XVI e o século XVII tiveram a importância de divulgar a língua japonesa no Ocidente, sem que influenciassem os estudos posteriores da

4 O primeiro estudo do gênero teria sido 雨集大概抄 (Tenihataigaishô), provavelmente do início do período Muromachi (1333-1573). Ver KOIKE, 1995: 194.

Uma síntese das principais contribuições desses autores encontra-se em SUZUKI, 1973.

Alguns autores apontam que houve algumas obras precedentes, sendo provavelmente a primeira Arte da Língua Japoneza, de Duarte da Silva, considerado anterior a 1564 (SUZUKI, 1973: 108), que, no entanto, nenhum exemplar se encontra preservado atualmente (MATSUMURA, 1973: 10).

7 Uma obra escrita em espanhol foi elaborada por Melchor Oyanguren, Arte de la Lengua Japona, publicada no México, em 1738, portanto um século após Collado (MATSUMURA, ibid.). 
gramática japonesa, sobretudo aqueles feitos pelos nativos ${ }^{8}$. Essa influência viria a acontecer dos chamados rangaku, "estudos holandeses", que marcaram o desenvolvimento das Ciências Naturais no Japão e, nessa esteira, também os estudos da língua japonesa.

Tsurumine Shigenobu (1788-1859) é o representante dessa nova corrente. Em 1831, publica Gogakushinsho, "Novo Tratado da Língua Japonesa", primeira obra de gramática escrita em japonês por um nativo, baseando-se em gramática ocidental, no caso a holandesa. Nesta obra, os pronomes são classificados como kaekotoba, literalmente "palavras que substituem" (SUZUKI, 1973: 114). O termo daimeishi, "pronome", surge, pela primeira vez, nessa fase, constando em Aokigahara (1854), de Maeda Toshiyasu (1800-59), estudioso de japonês (KOKUGOGAKKAI, 1980: 580).

$\mathrm{Na}$ segunda metade do século XIX, daimeishi passa, aos poucos, de simples tradução do termo pronome das gramáticas ocidentais a um termo gramatical, de fato, dos estudos japoneses, designando uma classe específica da língua japonesa. Como estudos representativos desse período, destacam-se Shôgaku Nihon Bunten, "Pequena Gramática Japonesa", de Tanaka Yoshikado, de 1874, e Nihon Bunten, "Gramática Japonesa", de Nakane Kiyoshi, obra de 1876. No estudo de Tanaka, o daimeishi é definido como "as palavras que substituem o nome das coisas" Nakane pouco acrescenta a esta definição (SUZUKI, op.cit.: 116-20).

A consolidação do termo daimeishi ocorre com Gohôshinan, "Instruções sobre o Emprego das Palavras" em Daigenkai, de 1889, de Ôtsuki Fumihiko (1847-1928), que procura conciliar as contribuições dos estudos vernaculares, originários do período Edo (1603-1867), e as das gramáticas ocidentais. Nessa obra, Ôtsuki define o daimeishi como um tipo de meishi, "substantivo", que substitui um nome e refere-se ao mesmo ${ }^{10}(1950: 5-6)$. Chama atenção, ainda, o fato de Ôtsuki ter afirmado, na introdução dos shijidaimeishi, "pronomes demonstrativos", que "os daimeishi substituem a posição dos substantivos"11 (op.cit.: 6). Esta afirmação será contestada pelos autores posteriores, sobretudo Yamada Yoshio e Hashimoto Shinkichi.

Segundo a classificação de Ôtsuki, os jindaimeishi são aqueles que são empregados referindo-se a pessoas ${ }^{12}$ e, de acordo com a "posição" (ichi) dessas pessoas,

8 Isto não quer dizer que os ocidentais deixaram de elaborar outras gramáticas da língua japonesa. Cerca de uma dezena de autores publicaram trabalhos relacionados com a língua japonesa nessa época, destacando-se James C. Hepburn, autor de A Japanese and English Dictionary, de 1867. Em detalhes, ver MATSUMURA, op.cit., p.14 e ss.

$9 \quad$ No original, "butsumei ni kauru kotobanari".

10 No original, "jibutsuno nani kaete korewo sashite iu"

11 No original, "daimeishi wa meishi no chii ni kawarite tatsumono naru". Esta postura faz recordar as considerações de Bloomfield (1935), qualificando os pronomes como substitutos. Entre os autores brasileiros, Celso Cunha e Luís Cintra definem os pronomes como palavras que "desempenham na oração as funções equivalentes às exercidas pelos elementos nominais", servindo para "representar um substantivo", e afirmam que, particularmente, os pronomes pessoais caracterizam-se por "denotarem as três pessoas gramaticais", tendo a "capacidade de indicar no colóquio" quem fala (primeira pessoa), com quem se fala (segunda pessoa) e de quem se fala (terceira pessoa) (1985: 268-9). 
diferentes daimeishi são empregados. Esta distinção é denominada ninshô, literalmente, "referência à pessoa" (op.cit.: 6). O ninshô se divide em três, a saber: jishô, que tem a propriedade de ser "empregado pela 'pessoa que fala', substituindo o próprio nome", taishô, que é "empregado pela 'pessoa que fala', substituindo o nome da pessoa com quem 'está de frente' e para quem dirige a palavra", e tashô, que "substitui o nome da 'outra pessoa' que aparece na fala dos dois"'3(ibid.).

As definições de jishô, taishô e tashô podem assim ser sistematizadas:

\begin{tabular}{|l|l|l|}
\hline ninshô & referente & exemplos \\
\hline jishô & "pessoa que fala" & ware (eu) \\
\hline taishô & "pessoa que está de frente" & nanji (tu) \\
\hline tashô & "outra pessoa" & kare, are (ele (a)) \\
\hline
\end{tabular}

O futeishô, ou seja, "ninshô indefinido", no caso tare ou dare (quem), é empregado de forma similar ao tashô, apenas quando não se pode identificar a pessoa ou o nome da pessoa referida: ${ }^{14}$

\begin{tabular}{|l|l|l|}
\hline ninsh $\hat{\boldsymbol{o}}$ & referente & exemplos \\
\hline futeishô(um tipo de tashố) & $\begin{array}{l}\text { pessoa desconhecida ou de uma } \\
\text { pessoa da qual não se conhece o nome }\end{array}$ & $\begin{array}{l}\text { tare (dare) } \\
\text { (quem) }\end{array}$ \\
\hline
\end{tabular}

Esta terminologia inaugurada por Ôtsuki, que classifica quatro tipos de ninshô, será adotada pelos estudiosos subseqüentes, alterando-se substancialmente a sua definição.

\section{2 - Posição de Yamada Yoshio}

A importância de Yamada Yoshio (1873-1958) deve-se ao fato de ter sido o primeiro lingüista a realizar um estudo da gramática japonesa com pretensão de ser completo. Nesse sentido, foi o primeiro lingüista a dar uma atenção maior à classe de daimeishi da língua japonesa.

Em Nihon Bunpôron, "Teoria da Gramática Japonesa", publicado em 1908, Yamada define o daimeishi como um tipo de taigen $^{15}$ que "indica algo real indiretamente, sem expressá-lo diretamente"16 (1970: 187). É necessário destacar que Yamada

13 Respectivamente, "hanasuhito, mizukara onoreganani kaete mochiiru", "wareto aitaishi, waga hanashikakuru hitono nani kaete iu" " "futarino aidani hanashidasu, tanohitono nani kaete iu" no original.

14

is Grupo de vocábulos que expressam um gainen (conceito). Divide-se em jittaigen, "taigen real", que expressa diretamente um conceito concreto, compreendendo o meishi (substantivo) e keishikitaigen, "taigen pró-forma", que expressa indiretamente um conceito amplo, compreendendo o daimeishi (pronomes), considerado shukantekikeishikitaigen, "taigen pró-forma de caráter pessoal", e sûshi (numerais), considerado kyakkantekikeishikitaigen, "taigen pró-forma de caráter impessoal" (YAMADA, 1970: 176-179).

16 "Jittai sonomonowo chokusetsuni arawasazushite, tada sorewo kansetsuni shijiserumononari", no original. 
não emprega o termo jindaimeishi, sendo este tratado juntamente com os demais pronomes, classificados em shijidaimeishi, "pronomes demonstrativos", pelos autores predecessores, como Ôtsuki Fumihiko. Assim, Yamada classifica o daimeishi em hanshashiji no daimeishi, "pronome reflexivo"17 e em shôkakushiji no daimeishi, "pronome de indicação relativa" 18 , do qual faz parte o que aqui denominamos jindaimeishi. Yamada afirma que este último compreende os pronomes que apresentam diferenças na forma de indicação de algo real, de acordo com a intenção do falante (op.cit.: 188). Em outras palavras, é possível afirmar que, para Yamada, shôkakushiji no daimeishi trata de pronomes que podem indicar coisas distintas, dependendo da intenção do falante, em cada caso e em situação distintos. Shôkaku surge, nesse contexto, como a expressão do ponto de vista pessoal, delimitado pela necessidade da comunicação que é casual e imediata e, nesse sentido, seu referente é relativo.

Yamada afirma que existem três tipos básicos de shôkaku (op.cit.: 188-92). O primeiro é empregado quando o falante se refere a si próprio e é denominado de daiisshô, "primeira pessoa", ou jisho, "autodesignativo" O segundo tipo comporta os pronomes empregados quando o falante se refere a seu interlocutor [taishu], aquele que "recebe a sua fala", denominado dainishô, "segunda pessoa" ou taishô, "contradesignativo"19 Nesses dois casos, o referente precisa ser necessariamente um humano ou, no mínimo, um ser personificado. Os pronomes daisanshô, "terceira pessoa", ou tashô, "heterodesignativo" 20 , indicam todos os elementos citados na fala, podendo ser pessoas, objetos, lugares e direções ${ }^{21}$ Estes podem indicar algo definido ou indefinido e, sendo assim, podem ser classificados em teishô, "pessoa definida", e futeishô, "pessoa indefinida" Os teishô podem, ainda, ser classificados em kinshô, quando indicam algo espacial ou psicologicamente próximo do falante; em chûshô, quando próximo do interlocutor e em ensh $\hat{o}$, nos demais casos, quando não preenche nenhuma dessas condições anteriores. O quadro seguinte sistematiza a classificação de Yamada ${ }^{22}$ :

\begin{tabular}{|l|l|}
\hline ninshô & exemplos \\
\hline $\begin{array}{l}\text { daiisshô } \\
\text { "1 pessoa" }\end{array}$ & $\begin{array}{l}\text { wa, ware, a, are } \\
\text { "eu" }\end{array}$ \\
\hline $\begin{array}{l}\text { dainisho } \\
\text { "2 } 2^{\mathrm{a}} \text { pessoa" }\end{array}$ & $\begin{array}{l}\text { na, nare, nanji } \\
\text { "tu" }\end{array}$ \\
\hline
\end{tabular}

17 Semelhante ao pronome reflexivo do português, trata-se de onore, "si próprio".

18 Esta tradução será esclarecida nas linhas seguintes.

19 Do ponto de vista da lingüistica ocidental, seria o destinatário, o tu que se complementa, que é oposto ao $e u$, do eixo eu-tu.

20 Da mesma forma aludida na nota 19 , refere-se a "outros" elementos fora do eixo eu-tu.

21 Esta posição aparentemente inusitada não é exclusiva de Yamada Yoshio, sendo compartilhada por gramáticos ocidentais. Numa concepção bastante similar à de Yamada, Karl Bühler (1961) apontou a proximidade entre os pronomes de terceira pessoa e demonstrativos. John Lyons destaca as particularidades da categoria de terceira pessoa, que "pode combinar-se com noções diversas, como "definido" $e$ "próximo" ou "remoto" e "podem referir-se a seres humanos, a animais e a coisas" (1987: 291 e 292).

Quadro adaptado do original apresentado por Yamada (1970: 190). 


\begin{tabular}{|l|l|l|l|l|}
\hline $\begin{array}{l}\text { daisanshô } \\
\text { "3a pessoa" }\end{array}$ & $\begin{array}{l}\text { hito } \\
\text { "pessoa" }\end{array}$ & $\begin{array}{l}\text { jibutsu } \\
\text { "coisa" }\end{array}$ & $\begin{array}{l}\text { basho } \\
\text { "lugar" }\end{array}$ & $\begin{array}{l}\text { hôkô } \\
\text { "direção" }\end{array}$ \\
\hline $\begin{array}{l}\text { teishô } \\
\text { kinshô }\end{array}$ & $\begin{array}{l}\text { ko,kore } \\
\text { "esta" }\end{array}$ & $\begin{array}{l}\text { ko, kore } \\
\text { "isto" }\end{array}$ & $\begin{array}{l}\text { koko } \\
\text { "aqui" }\end{array}$ & $\begin{array}{l}\text { kochi, konata } \\
\text { "lado de cá" }\end{array}$ \\
\hline $\begin{array}{l}\text { teishô } \\
\text { chûshô }\end{array}$ & $\begin{array}{l}\text { so,sore } \\
\text { "essa" }\end{array}$ & $\begin{array}{l}\text { so,sore } \\
\text { "isso" }\end{array}$ & $\begin{array}{l}\text { soko } \\
\text { "ai" }\end{array}$ & $\begin{array}{l}\text { sochi,sonata } \\
\text { "seu lado" }\end{array}$ \\
\hline $\begin{array}{l}\text { teishô } \\
\text { enshô }\end{array}$ & $\begin{array}{l}\text { a, are, } \\
\text { ka, kare }\end{array}$ & $\begin{array}{l}\text { a, are, } \\
\text { ka, kare } \\
\text { "aquilo" }\end{array}$ & $\begin{array}{l}\text { kashiko, asoko, } \\
\text { ashiko } \\
\text { "lá" }\end{array}$ & $\begin{array}{l}\text { achi, wochi, } \\
\text { kanata, anata } \\
\text { "lado de lá" }\end{array}$ \\
\hline futeishô & $\begin{array}{l}\text { ta, tare } \\
\text { "quem" }\end{array}$ & $\begin{array}{l}\text { izure, nani } \\
\text { "qual" }\end{array}$ & $\begin{array}{l}\text { izuku, izuko, izura } \\
\text { "onde" }\end{array}$ & $\begin{array}{l}\text { izuchi, izukata } \\
\text { "qual lado" }\end{array}$ \\
\hline
\end{tabular}

Pode-se notar que, em comparação com a sistematização de Ôtsuki, verifica-se uma maior ênfase na intencionalidade do falante, que constitui o cerne da definição de shôkaku, "pessoa", conforme acima tratado, uma vez que os chamados shijidaimeishi, "pronomes demonstrativos", foram incluídos ao lado dos chamados jindaimeishi, "pronomes pessoais"

Em Nihon Bunpô Kôgi (Curso de Gramática Japonesa), de 1922, segundo trabalho de estudo gramatical, Yamada procura redefinir o conceito de daimeishi e afirma que o sentido de daimeishi é "substituir o nome"23 e não um meishi, "substantivo", como sustentara Ôtsuki. Para Yamada, o meishi é empregado como meimoku [as name], e o daimeishi é empregado como substituto de um meimoku [for name] (1971: 27). Assim, o daimeishi é considerado um taigen empregado para se referir às coisas ${ }^{24}$, substituindo o seu nome (ibid.)

Nesta obra, Yamada procura fazer observações contrastivas com as gramáticas ocidentais, ao mesmo tempo em que retoma a teoria desenvolvida em Nihon Bunpôron. Nesse sentido, o principal traço distintivo desta obra é a comparação do japonês com outras línguas, notadamente com o inglês, e verifica-se uma maior preocupação com as definições, sempre tendo em vista aquelas do Ocidente. É na esteira desta orientação que se descobre a origem do termo daimeishi. Segundo Yamada, este termo originou-se da tradução do inglês pronoun, que, por sua vez, vem do latim pronomen (ibid.).

Nessa linha, pela primeira vez, Yamada admite que o shôkaku é equivalente ao person da bibliografia ocidental (op.cit.: 22), mantendo, entretanto, o caráter de intencionalidade do falante e o caráter ocasional do referente. Continuando a fazer um estudo comparativo com as línguas ocidentais, o lingüista destaca as propriedades dos pronomes da língua japonesa, como a inexistência do gênero, da forma própria para $o$

${ }^{24}$ No original, "jibutsu wo sasu" 
número ${ }^{25}$ (YAMADA, 1971: 32-3), considerações que, vale ressaltar, foram feitas na primeira obra, mas aqui mais detalhadas, inclusive com exemplos do inglês. No mais, Yamada mantém a classificação dos pronomes de Nihon Bunpôron, com alguns acréscimos pontuais, como a inclusão da categoria tempo, ao lado dos fatores psicológicos e espaciais, para a determinação de kinshô, chûshô e enshô. Observa-se, ainda, algumas mudanças de terminologia e a inclusão de alguns pronomes em detrimento de outros, em comparação com a tabela anterior ${ }^{26}$ :

\begin{tabular}{|l|l|}
\hline ninshô & exemplos \\
\hline $\begin{array}{l}\text { daiichininshô } \\
\text { (jishô) }\end{array}$ & (wa) ware \\
"1a pessoa" & (watakushi) \\
\hline $\begin{array}{l}\text { dainininshô } \\
\text { (taishô) }\end{array}$ & (na) nare \\
"2a pessoa" & nanji, kimi (omae) \\
\hline
\end{tabular}

\begin{tabular}{|l|l|l|l|l|}
\hline ninshô & \multicolumn{4}{|c|}{ exemplos } \\
\hline $\begin{array}{l}\text { daisanninshô } \\
\text { (tashô) } \\
\text { "3" pessoa" }\end{array}$ & $\begin{array}{l}\text { hito } \\
\text { "pessoa" }\end{array}$ & $\begin{array}{l}\text { jibutsu } \\
\text { "coisa" }\end{array}$ & $\begin{array}{l}\text { basho } \\
\text { "lugar" }\end{array}$ & $\begin{array}{l}\text { hôkô } \\
\text { "direção" }\end{array}$ \\
\hline $\begin{array}{l}\text { teishô } \\
\text { kinshô }\end{array}$ & $\begin{array}{l}\text { ko,kore } \\
\text { "esta" }\end{array}$ & $\begin{array}{l}\text { ko, kore } \\
\text { "isto" }\end{array}$ & $\begin{array}{l}\text { koko } \\
\text { "aqui" }\end{array}$ & $\begin{array}{l}\text { kochi, konata } \\
\text { "lado de cá" }\end{array}$ \\
\hline $\begin{array}{l}\text { teishô } \\
\text { chûshô }\end{array}$ & $\begin{array}{l}\text { so,sore } \\
\text { "essa" }\end{array}$ & $\begin{array}{l}\text { so,sore } \\
\text { "isso" }\end{array}$ & $\begin{array}{l}\text { soko } \\
\text { "ai"" }\end{array}$ & $\begin{array}{l}\text { sochi,sonata } \\
\text { "seu lado" }\end{array}$ \\
\hline $\begin{array}{l}\text { teishô } \\
\text { enshô }\end{array}$ & $\begin{array}{l}\text { a, are, } \\
\text { ka, kare } \\
\text { "aquela" }\end{array}$ & $\begin{array}{l}\text { a, are, } \\
\text { ka, kare } \\
\text { "aquilo" }\end{array}$ & $\begin{array}{l}\text { kashiko, asoko, } \\
\text { ashiko } \\
\text { "lá" }\end{array}$ & $\begin{array}{l}\text { achi, wochi, } \\
\text { kanata, anata } \\
\text { "lado de lá" }\end{array}$ \\
\hline futeishô & $\begin{array}{l}\text { ta, tare } \\
\text { "quem" }\end{array}$ & $\begin{array}{l}\text { izure, nani } \\
\text { "qual" }\end{array}$ & $\begin{array}{l}\text { izuku, izuko, izura } \\
\text { "onde" }\end{array}$ & $\begin{array}{l}\text { izuchi, izukata } \\
\text { "qual lado" }\end{array}$ \\
\hline
\end{tabular}

No mesmo ano de 1922, Yamada publicou outro trabalho de estudo gramatical intitulado Nihon Kôgohô Kôgi (Curso de Língua Moderna Japonesa). Nesta obra, o lingüista faz uma explanação sem nenhuma inovação sobre os pronomes, entretanto, apresenta um quadro de daimeishi bastante próximo do atual (1970b: 38$)^{27}$, como segue:

25 No japonês, o plural dos pronomes é obtido pela coadjuvação de sufixos que indicam a pluralidade (ex.: ra de warera (nós), ou pela repetição dos termos, o chamado tatamigo (ex.: ware (eu) e wareware (nós)). O item lexical equivalente a nós ou vós do português inexistem no japonês.

26 Quadro adaptado do original (1971: 36-37). Os parênteses são de Yamada.

27 Tabela adaptada do original. Os parênteses são de Yamada. 


\begin{tabular}{|l|l|}
\hline ninshô & exemplos \\
\hline daiisshôkaku & watakushi, watashi \\
(jishô) & (ware), (ore), (boku) \\
"1ª pessoa" & "eu" \\
\hline dainishôkaku & anata, omae \\
(taishô) & (kimi) \\
"2 $2^{\mathrm{a}}$ pessoa" & "tu" \\
\hline
\end{tabular}

\begin{tabular}{|c|c|c|c|c|}
\hline ninshho & \multicolumn{4}{|c|}{ exemplos } \\
\hline $\begin{array}{l}\text { daisanshôkaku } \\
\text { (tashô) } \\
\text { "3a pessoa" }\end{array}$ & $\begin{array}{l}\text { hito } \\
\text { "pessoa" }\end{array}$ & $\begin{array}{l}\text { jibutsu } \\
\text { "coisa" }\end{array}$ & $\begin{array}{l}\text { basho } \\
\text { "lugar" }\end{array}$ & $\begin{array}{l}\text { hôkô } \\
\text { "direção" }\end{array}$ \\
\hline $\begin{array}{l}\text { teishô } \\
\text { kinshô }\end{array}$ & $\begin{array}{l}\text { kore } \\
\text { "esta" }\end{array}$ & $\begin{array}{l}\text { kore } \\
\text { "isto" }\end{array}$ & $\begin{array}{l}\text { koko } \\
\text { "aqui" }\end{array}$ & $\begin{array}{l}\text { kotchi, kochira } \\
\text { "lado de cá" }\end{array}$ \\
\hline $\begin{array}{l}\text { teishô } \\
\text { chûshô }\end{array}$ & $\begin{array}{l}\text { sore } \\
\text { "essa" }\end{array}$ & $\begin{array}{l}\text { sore } \\
\text { "isso" }\end{array}$ & $\begin{array}{l}\text { soko } \\
\text { "aí" }\end{array}$ & $\begin{array}{l}\text { sotchi,sochira } \\
\text { "seu lado" }\end{array}$ \\
\hline $\begin{array}{l}\text { teishô } \\
\text { enshô }\end{array}$ & $\begin{array}{l}\text { are, } \\
\text { "aquela" }\end{array}$ & $\begin{array}{l}\text { are, } \\
\text { "aquilo" }\end{array}$ & $\begin{array}{l}\text { asuko } \\
\text { "lá" }\end{array}$ & $\begin{array}{l}\text { atchi, achira } \\
\text { "lado de lá" }\end{array}$ \\
\hline futeishô & $\begin{array}{l}\text { donata,dare } \\
\text { "quem" }\end{array}$ & $\begin{array}{l}\text { dore, nani } \\
\text { "qual" }\end{array}$ & $\begin{array}{l}\text { doko } \\
\text { "onde" }\end{array}$ & $\begin{array}{l}\text { dotchi, dochira } \\
\text { "qual lado" }\end{array}$ \\
\hline
\end{tabular}

\section{3 - Posição de Matsushita Daizaburô}

A contribuição de Matsushita Daizaburô $(1878$ - 1935) sobre os pronomes pessoais do japonês pode ser encontrada na sua obra representativa Kaisen Hyôjun Nihonbunpô, "Gramática Padrão Japonesa Reformulada", de 1928.

Nesta obra, Matsushita defende que os daimeishi não devem ser tratados à parte da classe dos meishi, uma vez que apresentam natureza gramatical semelhante (1928: 195). Além disso, o lingüista vê contradição em classificar por exemplo $m o n o^{28}$ como keishikimeish ${ }^{29}$, portanto, um tipo de meishi, e dare como daimeishi, comumente feito por outros autores (op.cit.: 225). Assim, Matsushita defende que tanto um como outro sejam tratados como uma subclasse de meishi, sendo que, no exemplo acima, dare seria classificado na de miteimeishi , "substantivo indefinido", reservando à subclasse de daimeishi aqueles propriamente ditos, como ware e kore.

Literalmente "indivíduo", empregado para se referir a alguém sem especificação.

Substantivo pró-forma. Apresenta características morfológicas e sintáticas similares a um substantivo, entretanto, o conteúdo semântico não é fixo, sendo definido de acordo com o complemento. 
Para Matsushita, ninshôdaimeishi consiste em pronomes empregados pelo falante que, tendo a si como referência, faz a distinção de si dos outros ${ }^{30}$. Dessa forma, daiichininshô é empregado quanto o falante se refere a si próprio, dainininshô é empregado quando o falante se refere ao interlocutor e daisanninshô, quando se refere aos demais casos, ou seja, excluindo-se a si próprio e o interlocutor (op.cit.: 232).

A seguir, apresenta-se um quadro de sistematização dos pronomes pessoais segundo Matsushita, com os respectivos exemplos:

\begin{tabular}{|l|l|l|}
\hline ninshô (pessoa) & bungo (língua escrita) & kôgo (língua falada) \\
\hline daiichininshô & ware, yo, soregashi, shôsei, wareware & watakushi, boku, temae, daik $\hat{o}^{31}$ \\
\hline dainininshô & nanji, kimi, sokka ${ }^{32}$, kika, shokun & anata, gozen, kisama \\
\hline daisanninshô & kare & yatsu \\
\hline
\end{tabular}

A contribuição de Matsushita no que se refere aos pronomes se limita a isso. Fazendo uma comparação com Yamada, pode-se afirmar que deu pouca ênfase a essa classe, ou melhor, não admitia que constituísse uma classe independente à parte dos substantivos. Entretanto, embora não seja admitido publicamente, pode-se afirmar que influenciou o estudo posterior de Tokieda, no que se refere à sua terminologia, e também na ênfase que deu na figura do falante.

\section{4 - Posição de Sakuma Kanae}

Também contemporâneo de Yamada Yoshio, Sakuma Kanae (1888-1970) deu importantes contribuições para a teoria de daimeishi, em Gendai Nihongo no Hyôgen to Gohô (Gramática e Expressões do Japonês Contemporâneo), publicado em 1936. Nesse trabalho, embora tenha dado maior atenção ao shijidaimeishi, incluiu na discussão importantes pontos para a compreensão dos pronomes pessoais do japonês.

No capítulo intitulado "Daimeishi no Honryô" "Essência dos Pronomes" Sakuma revisa os principais trabalhos sobre daimeishi e compartilha a tese de Yasuda Kiyomon ${ }^{33}$, que afirma ser completamente equivocada a definição de daimeishi como as palavras que

30 No original, setsuwasha (shisôsha) ga jikowo kijuntoshite jitawo kubetsusuru. Embora Matsushita não considerasse ainda o nível discursivo, é de se destacar a sua percepção que expressa uma inspiração nesse sentido, muito anterior aos estudos posteriores sobre o discurso. Ainda sobre o assunto, John Lyons destaca o caráter egocêntrico da situação de enunciação, afirmando que "o falante está sempre no centro da situação do enunciado" (1987: 291). Assim define Lyons: "A "primeira" pessoa é usada pelo falante, ao referir-se a si mesmo como sujeito do discurso. A "segunda" pessoa é por ele usada para referir-se ao ouvinte. A "terceira" é usada pra referir-se a pessoas ou coisas que não sejam falante e ouvinte" (ibid.).

31 乃公, no original.

32 足下, no original.

33 Linguiista, autor de Kokugohô Gaisetsu (Teoria Geral de Gramática da Língua Nacional), publicado em 1928. 
substituem o meishi, "substantivo", ou meishô, "nome", pois, se a essência dos pronomes fosse essa, um substantivo que substituísse um outro teria que consistir em pronome, o que não é verdadeiro. Segundo a tese de Yasuda, o meishi trata de um "registro sonoro de um atributo peculiar de uma existência concreta"34, e o daimeishi apresenta uma natureza totalmente distinta. Segundo Yasuda, este precisa ser tratado como um taigen que possui a especificidade de indicar uma 'existência concreta' [jittai], "construindo um foco comum de atenção entre os interlocutores"35 , em suma, com a finalidade de indicar as coisas $^{36}$ (Sakuma, 1966: 4). Sakuma afirma, ainda, que embora Yamada tenha destacado a função dos pronomes de "indicar as coisas", a essência não está no fato de isso ocorrer de forma direta ou indireta, como afirmara em Nihon Bunpôron (1970: 187).

Como se pode constatar, a discussão de Sakuma gira em torno dos pronomes demonstrativos, mas o ponto importante é a correspondência entre os shijidaimeishi e os jindaimeishi relacionados ao que denomina "sistema ko-so-a-do" O "sistema ko" (kore, kochira etc) indica algo (objetos, lugares etc) pertencente ao "domínio" (nawabari) ${ }^{37}$ do falante, o "sistema so" (sore, sochira etc) indica algo pertencente ao "domínio" do interlocutor, o "sistema $a$ " (are, achira etc) indica algo do "domínio" de outrem e, por final, o "sistema do" (dore, doko etc) indicando algo indefinido (op.cit.: 35). Sakuma observa que os sistemas " $k o$ ", "so" e " $a$ ", originariamente pronomes demonstrativos, podem inclusive ser empregados como pronomes pessoais, como, por exemplo, kochira se referindo a eu / nós, sochira a tu / vós e achira a eles / elas, configurando o fenômeno denominado shijidaimeishi no ten-yô, "conversão de pronomes demonstrativos" (1966: 36).

Dessa forma, Sakuma contesta a sistematização feita por Yamada Yoshio, que classifica os chamados shijidaimeishi como pertencendo apenas ao daisanshôkaku, "terceira pessoa" (1995: 259) e propõe uma nova classificação, levando em consideração o "domínio" dos interlocutores (op.cit.: 260):

\begin{tabular}{|c|c|c|}
\hline & $\begin{array}{c}\text { taiwasha no sô } \\
\text { "nível dos interlocutores" }\end{array}$ & $\begin{array}{c}\text { shozokujibutsu no sô } \\
\text { "nível dos fatos e das coisas" }\end{array}$ \\
\hline $\begin{array}{l}\text { hanashite } \\
\text { "falante" }\end{array}$ & $\begin{array}{c}\text { (para o próprio falante) } \\
\text { watakushi, watashi, "eu" }\end{array}$ & $\begin{array}{l}\text { (domínio do falante) } \\
\text { kokei, "sistema ko" }\end{array}$ \\
\hline $\begin{array}{l}\text { hanashiaite } \\
\text { "interlocutor" }\end{array}$ & $\begin{array}{l}\text { (para o interlocutor) } \\
\text { anata, omae, "tu" }\end{array}$ & $\begin{array}{l}\text { (domínio do interlocutor) } \\
\text { sokei, "sistema so" }\end{array}$ \\
\hline $\begin{array}{l}\text { hatanomono } \\
\text { "outras coisas" }\end{array}$ & 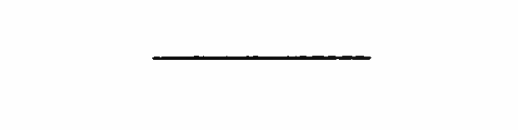 & $\begin{array}{l}\text { (para outras coisas) } \\
\text { akei, "sistema } a "\end{array}$ \\
\hline $\begin{array}{c}\text { futei } \\
\text { "indefinido" }\end{array}$ & donata, dare, "quem" & dokei, "sistema do" \\
\hline
\end{tabular}

34 No original, "jittai no tokuyûsei no seionteki kisai".

35 No original, "taiwasha no aida ni kyôtsûtekina chûi no shôten wo tsukuru"

36 No original, "mono wo sasu taigen"

37 Sakuma considera que quando dois interlocutores dialogam, há o estabelecimento de uma espécie de território abstrato, denominado nawabari, aqui traduzido como domínio, demarcando claramente o espaço de cada um e que é levado em consideração no discurso. 


\section{5 - Posição de Tokieda Motoki}

Tokieda Motoki (1900-1967) pode se comparar a Yamada Yoshio no que se refere à teorização dos pronomes da língua japonesa, assumindo, porém, uma postura diferente. Em Nihon Bunpô Kôgohen, "Gramática Japonesa - Série Língua Moderna", publicado em 1950, Tokieda classifica os daimeishi em meishiteki daimeishi, "pronomes de natureza substantiva", em rentaishitekidaimeishi, "pronomes de natureza adjetiva", e em fukushitekidaimeishi, "pronomes de natureza adverbial", realizando, portanto, análise de perfil morfossintático. Entre estes, Tokieda destaca os ninshôdaimeish ${ }^{38}$, que na classificação acima faz parte dos meishiteki daimeishi, considerando-os o mais representativo dos daimeishi (1978: 62).

Tokieda afirma que a especificidade dos ninshôdaimeishi reside no fato de estes expressarem a "concepção da relação com o falante" 39 (op.cit.: 63), ou seja, eles são empregados exclusivamente para expressar a relação do falante [hanashite] com os fatos, incluindo-se os interlocutores, e coisas [jibutsu] (op.cit.: 62).

Essa concepção de ninshô daimeishi tem como base a visão de Tokieda no que se refere ao ato $\mathrm{e}$ às circunstâncias da enunciação ${ }^{40}$, o que significa, em última instância, compreender como ele concebe a própria língua. Em Kokugogaku Genron, "Princípios de Gramática Japonesa", de 1941, Tokieda considera que as condições primordiais para a realização da língua são três: shutai, "sujeito do ato lingüístico", bamen, "contexto", e sozai, "matéria" (1969: 40). Shutai constitui o falante [hanashite], aquele que se expressa lingüisticamente, sem o qual não ocorre o ato lingüístico"1 (op.cit.: 41). O bamen compreende o próprio espaço físico onde ocorre a enunciação, e mais, inclui o ouvinte [kikite] e ainda os sentimentos e as emoções do próprio falante em relação a esses elementos (op.cit.: 43). Dessa forma, o bamen constitui um constructo mental elaborado pelo falante, constructo este que possui dois componentes, a saber, o cenário (incluindose o ouvinte) apreendido pela percepção e os sentimentos, as emoções e as atitudes

38 Tokieda emprega o termo ninshôdaimeishi como sinônimo de jindaimeishi. O presente trabalho adotará essa postura neste item, a despeito de definição de ninshô feita por Yamada Yoshio.

39 No original, "hanashitetono kankei gainen".

40 Os autores ocidentais modernos herdaram o legado deixado por Apolônio Díscolo, da divisão dos pronomes em dêixis, que aponta para os objetos presentes, e anáfora, que se refere ao ausente, mas já conhecido (SILVA, 1972: 47). Um dos expoentes desses lingüistas, Émile Benveniste considerou a dêixis "contemporânea da instância de discurso que contém o indicador de pessoa" (1976: 280). Assim, os pronomes pertencem, tal qual uma dêixis, às "instâncias do discurso", ou seja, "os atos discretos e cada vez únicos pelos quais a lingua é atualizada em palavra por um locutor" (op.cit.: 277). Nessa perspectiva, Benveniste define o eu como o "individuo que enuncia a presente instância de discurso que contém a instância lingüistica eu" (op.cit.: 279) e o tu como o "indivíduo alocutado na presente instância de discurso contendo a instância lingüistica tu" (ibid.). Para Benveniste, ele não possui a noção de pessoa, pois "representa de fato o membro não marcado da correlação de pessoa" (op.cit.: 282). É possível afirmar que a concepção de instância de discurso, acima referida, feitas as ressalvas necessárias, se assemelha muito com a concepção de Tokieda.

4] É importante destacar que o shutai é diferente do sujeito do enunciado, ou seja, o sujeito da sentença que foi enunciada pelo falante. 
acarretados ou despertados por esta percepção. Obviamente, sendo um constructo mental do falante, o bamen só se realiza na existência deste ${ }^{42}$ (op.cit.: 44). Por final, o sozai compreende as coisas [jibutsu], os conceitos [gainen] e as representações [hyôshô] apreendidos pela percepção do falante que se tornam "assuntos da sua fala" na atualização lingüística, ou seja, é "aquilo" sobre o qual se fala. (op.cit.: 50-1).

Se se aplicar essa concepção ao caso dos ninshôdaimeishi, vale repetir, as palavras que expressam a relação do falante [hanashite] com os fatos e coisas [jibutsu], chega-se à conclusão de que o jibutsu consiste em falante, ouvinte e terceiros que são tratados como sozai, "matéria", no ato lingüístico. Dessa forma, para Tokieda, "os pronomes de daiichininshô são empregados somente quando o falante expressa a si mesmo na condição de falante", os de dainininshô "quando o falante expressa o outro na condição de ouvinte", e por final, os pronomes de daisanninshô "quando o falante expressa o outro na condição de assunto da fala [wadai no jibutsu]" (1978: 63). Organizando em forma de diagrama o exposto, tem-se o seguinte quadro (1978: 68) ${ }^{43}$ :

\begin{tabular}{|c|c|c|c|c|}
\hline Relação com o falante & \multicolumn{4}{|c|}{ Tipos de assuntos (kotogara no shurui) } \\
\hline & pessoa & coisa & lugar & direção \\
\hline $\begin{array}{c}\text { falante } \\
\text { hanashite } \\
\text { (daiichininshô) }\end{array}$ & $\begin{array}{l}\text { watakushi, boku } \\
\text { "eu" }\end{array}$ & & & \\
\hline $\begin{array}{c}\text { ouvinte } \\
\text { kikite } \\
\text { (dainininshô) } \\
\end{array}$ & $\begin{array}{l}\text { anata, kimi } \\
\text { "tu" }\end{array}$ & & & \\
\hline $\begin{array}{l}\text { assuntos (kotogara) } \\
\text { (daisanninshô) }\end{array}$ & pessoa & coisa & lugar & direção \\
\hline kinshô & $\begin{array}{c}\text { konokata } \\
\text { “esta pessoa" }\end{array}$ & $\begin{array}{c}\text { ko } \\
\text { kore } \\
\text { "isto" }\end{array}$ & $\begin{array}{l}\text { koko } \\
\text { "aqui", }\end{array}$ & $\begin{array}{l}\text { kochira, kotchi } \\
\text { "lado de cá" }\end{array}$ \\
\hline chûshô & $\begin{array}{c}\text { sonokata } \\
\text { “essa pessoa" }\end{array}$ & $\begin{array}{c}\text { so } \\
\text { sore } \\
\text { "isso" }\end{array}$ & $\begin{array}{l}\text { soko } \\
\text { "aí" }\end{array}$ & $\begin{array}{c}\text { sochira } \\
\text { sotchi } \\
\text { "seu lado" }\end{array}$ \\
\hline enshô & $\begin{array}{c}\text { anokata } \\
\text { "aquela pessoa" }\end{array}$ & $\begin{array}{c}a \\
\text { are } \\
\text { "aquilo" }\end{array}$ & $\begin{array}{l}\text { asoko } \\
\text { "lá" }\end{array}$ & $\begin{array}{c}\text { achira } \\
\text { atchi } \\
\text { "lado de lá" }\end{array}$ \\
\hline futeishô & $\begin{array}{c}\text { donokata } \\
\text { donata } \\
\text { "qual pessoa" }\end{array}$ & $\begin{array}{c}\text { do } \\
\text { dore } \\
\text { "qual" }\end{array}$ & $\begin{array}{l}\text { doko } \\
\text { "onde" }\end{array}$ & $\begin{array}{c}\text { dochira } \\
\text { dotchi } \\
\text { "qual lado" }\end{array}$ \\
\hline
\end{tabular}

42 A ambigüidade do conceito de $b a$ fez com que Takahashi Tarô e outros propusessem a redefinição de ba em bamen, "situação objetiva de enunciado" e ba, "situação subjetiva de enunciado" (OKAMURA, 1972. Tradução dos termos de FUKASAWA, 1991). Segundo essa proposta, o bamen indicaria a 
Importante destacar que Tokieda considera pronomes de daisanninshô as locuções konokata, "esta pessoa", sonokata, "essa pessoa", anokata, "aquela pessoa", e donokata, "qual pessoa"44.

\section{6 - Posição de Hashimoto Shinkichi}

Hashimoto Shinkichi (1882-1945) é reconhecido por ter elaborado as bases da gramática que é lecionada nas escolas japonesas ${ }^{45}$ No que se refere ao daimeishi, entretanto, deu pouca atenção, permanecendo ao longo de sua atuação acadêmica sem contribuir para o aprofundamento do conhecimento referente a esta classe.

Hashimoto critica os teóricos predecessores sem citá-los, afirmando que o daimeishi não substitui substantivos nem nomes (meishô), tendo apenas a capacidade de indicar "coisas" (1967: 74.). Na sua sistematização, o daimeishi faz parte da classe de meishi, um taigen 46 , que possui a função de indicar as "coisas" (mono wo sasu) sem expressar o atributo (seishitsu) delas, podendo inclusive indicar as "coisas" cujos nomes são desconhecidos (ibid). Dessa forma, os poucos daimeishi citados pelo lingüista são koko, soko, kochira, achira e kono ${ }^{47}$

Como se verifica, nenhum jindaimeishi é citado, mais do que isso, o lingüista nem sequer se preocupa em classificar os tipos de daimeishi, restringindo as suas considerações em poucas linhas.

\section{3- Considerações finais}

A partir dessa revisão sucinta dos autores que realizaram o estudo teórico dos pronomes pessoais da língua japonesa, é possível fazer duas observações. Em primeiro lugar, a existência de duas posturas teóricas no que se refere à função dos prono-

relação formada por falante, ouvinte e "matéria", e o ba a relação formada por jibun,"si próprio", (o próprio falante), o aite, "interlocutor", (do falante) e o wazai, "assunto" (OKAMURA, 1972: 98). A extensão dessa discussão escapa aos propósitos do presente estudo.

43 Do original, foram excluídos os pronomes de "natureza adjetiva" e os de "natureza adverbial"

44 Embora fora do escopo do presente trabalho, cabe acrescentar que as variantes ko, so, a e do da coluna coisas, com a coadjuvação do morfema relacional no, formam os pronomes de "natureza adjetiva", respectivamente kono, "este", sono, "esse", ano, "aquele" e dono, "qual"

45 Conhecido por gakkôbunpô. Para os críticos, trata-se de uma gramática descritiva, que se propõe a fazer uma análise objetiva dos enunciados, sem nenhuma pretensão de se fazer teoria. NISHIDA, 1984: 132.

46 Na concepção de Hashimoto, taigen constitui as classes que expressam o conceito das coisas (jibutsu no gainen wo arawasu), no aspecto semântico, e formam o sujeito (shugo) e não possuem declinação (katsuyô), no aspecto morfossintático. Fazem parte do taigen: meishi (substantivos), incluindo daimeishi e sûshi (numeral) (HASHIMOTO, 1983: 398-99).

47 Sobre os quatro primeiros, Hashimoto admite expressar certo atributo, ou seja, lugar e direção, para os dois primeiros e dois últimos, respectivamente. 
mes: a de substituir os nomes, ou substantivos, dependendo do autor, e a de "indicar", "apontar" ou "referir", expressa pelo verbo sasu do japonês. Se a primeira possibilidade de definição, a de substituir, está descartada, a segunda se apresenta controversa. A ambigüidade das definições resultantes dessa segunda concepção originou os estudos que visam a definir o próprio sasu, como aquele que o considera como o ato de "relacionar, de expressar conceitualmente o referente (a ser expresso)"48 (Kashiwadani, 1984: 205). Nessa perspectiva, a relação falante - "matéria", como afirma Tokieda, apresenta-se de extrema importância, uma vez que só a partir dessa referência é possível ao falante estabelecer uma conceituação adequada para o objeto (referente), principalmente no japonês, cujo pronome apresenta uma profusão de formas para cada pessoa.

Em segundo lugar, é possível constatar semelhanças entre as discussões feitas pelos autores aqui tratados e aquelas feitas por lingüistas ocidentais. Isso se explica inicialmente pelo fato de a própria concepção de pronome ter se originado da gramática ocidental, mas há que se considerar, embora de forma preliminar, a universalidade das características dessa classe, pelo menos no japonês e nas principais línguas ocidentais $^{49}$.

De um modo geral, nota-se que, não obstante a riqueza das contribuições dos autores abordados neste trabalho, são poucos os pronomes tratados, e tampouco as explanações esclarecem a diferença entre os vários pronomes existentes para a mesma pessoa. Sobre o primeiro ponto, é possível explicar, em parte, pelo fato de que esses autores procuraram realizar um estudo abrangente da língua japonesa, constituindo os pronomes apenas mais uma das classes de palavras existentes. Assim, a teorização sobre os pronomes teria ficado demasiadamente generalizada. Entretanto, a explicação mais plausível, e válida também para o segundo ponto supramencionado, está no fato de que poucos foram, de fato, considerados pronomes legítimos, sendo outros considerados substantivos de natureza tratamental, empregados como pronomes por empréstimo lexical. E para considerar o emprego desses, assim como a diversidade na mesma pessoa, seria preciso levar em conta não somente o uso pragmático, mas também a interação em curso entre os interlocutores, enfoque este fora das pretensões dos autores aqui tratados.

Em suma, o mérito dos estudos dos autores clássicos aqui abordados está no fato de ter conseguido, de alguma forma, sistematizar a profusão de pronomes pessoais do japonês, alicerce sobre o qual os lingüistas posteriores puderam avançar para melhor elucidação dessa classe em questão.

Otto Jespersen foi um dos primeiros lingüistas a tratar do assunto dentro dos cânones da Lingüística nome dado por ele aos pronomes, retirado do shift, que, entre outros, significa "mudança", "revezamento" e "substituição alternada", fazendo alusão à sua natureza de comportar o uso variável, de acordo com cada contexto, que estabelece o próprio significado, ou seja, o significado advém do contexto da enunciação (1948: 123, apud Silva, 1972). 
BENVENISTE, Émile. Problemas de Lingüística Geral. São Paulo: Nacional/Edusp, 1976.

BLOOMFIELD, Leonard. Language. London: G. Allen \& Unwin, 1965.

BÜHLER, Karl. Teoria del Lenguage. Madrid: Revista de Occidente, 1961.

CUNHA, C. ; CINTRA, Luís F. L. Nova Gramática do Português Contemporâneo. São Paulo: Nova Fronteira, 1985.

FUKASAWA, Lídia M. O Sistema de Estruturação das Modalidades na Língua Japonesa. 1991. Tese de doutoramento - FFLCH/USP, São Paulo, 1991.

HAGA, Yasushi. Gendai Nihongono Bunpô (Gramática da Língua Japonesa Contemporânea). Tóquio: Kyôikushuppan, 1978.

HASHIMOTO, Shinkichi. Kokugotokushitsuron (Teoria das Propriedades da Língua Vernácula). Tóquio: Iwanami, 1983.

Kokubunpôtaikeiron (Teoria da Sistematização da Gramática Japonesa). Tóquio: Iwanami, 1967 [1959].

IKEGAMI, Akihiko. Daimeishino Hensen (Estudo Diacrônico dos Pronomes). In: SUZUKI, K.; HAYASHI, O. (Org.). Hinshibetsu Nihon Bunpô Kôza: Meishi/ Daimeishi (Curso de Gramática Japonesa: Classes - Substantivos e Pronomes). Tóquio: Meiji Shoin, 1971.

KASHIWADANI. Yoshihiro. Meishi, Daimeishino Shomondai (Questões de substantivos e pronomes). In: SUZUKI, K.; HAYASHI, O. (Org.). Kenkyû Shiryô Nihonbunpô Hinshiron Taigen hen (Estudos de Gramática Japonesa: Morfologia - Nomes). Tóquio: Meiji Shoin, 1984.

KOIKE, Seiji. Nihongowa ikani tsukuraretaka (Como a Língua Japonesa foi constituída). Tóquio: Tikumashobô, 1995.

LYONS, John. Linguagem e Lingüística. Rio de Janeiro: Guanabara Koogan, 1987. MATSUMURA, Akira. Yôbuntento hinshiron (Gramáticas do japonês elaboradas pelos estrangeiros e taxionomia). In: SUZUKI, K.; HAYASHI, Ôki (Org.). Hinshibetsu Nihon Bunpô Kôza: Hinshisôron (Curso de Gramática Japonesa por Classes: Teoria Morfológica Geral). Tóquio: Meiji Shoin, 1973.

MATSUSHITA, Daizaburô. Hyôjun Kaisen Nihonbunpô (Gramática Padrão Japonesa Reformulada). Tóquio: Kigensha, 1928.

NISHIDA. Naotoshi. Gobunrui no Rekishi (História da taxionomia). In: SUZUKI, K.; HAYASHI, O. (Org.). Kenkyû Shiryô Nihonbunpô Hinshiron Taigen hen (Estudos de Gramática Japonesa: Morfologia - Nomes). Tóquio: Meiji Shoin, 1984.

OKAMURA, Kazue. Daimeishitowa nanika. In: SUZUKI, K.; HAYASHI, O. (Org.). Hinshibetsu Nihon Bunpô Kôza: Meishi/Daimeishi (Curso de Gramática Japonesa: Classes - Substantivos e Pronomes). Tóquio: Meiji Shoin, 1972.

ÔTSUKI, Fumihiko. Gohôshinan (Instruções sobre o Emprego das Palavras). In Daigenkai (Grande Dicionário), vol. 4, Tóquio: Fuzanbô, 1950. 
SAKUMA, Kanae. Nihongono Tokushitsu (A Propriedade da Língua Japonesa). Tóquio: Kuroshio, 1995 [1936].

Gendai Nihongono Hyôgento Gohô (Gramática e Expressões do Japonês Contemporâneo). Tóquio: Kôseisha Kôseikan, 1966.

SUGUIMOTO, Tsutomu. Nihongo Kenkyûno Rekishi (História de Estudos da Língua Japonesa). Tóquio: Yasaka Shobô, 1998.

SHIMA, Shôzo (Org.). Rodriguez Nihon Daibunten. (Grande Gramática Japonesa de Rodriguez). Tóquio: Bunka Shobô Hakubunsha, 1969.

SILVA, Ignácio Assia da. A Dêixis Pessoal. 1972. Tese de doutoramento - FFLCH/ USP, São Paulo, 1972.

SUZUKI, Kazuhiko. Hinshibunruino Rekishito Gakusetsu (História e Teoria da Classificação Morfológica). In: SUZUKI, K.; HAYASHI, Ôki (Org.). Hinshibetsu Nihon Bunpô Kôza: Hinshisôron (Curso de Gramática Japonesa por Classes: Teoria Morfológica Geral). Tóquio: Meiji Shoin, 1973.

TOKIEDA, Motoki. Kokukogaku Genron (Princípios da Gramática Japonesa). 24a ed. Tóquio: Iwanami, 1969 [1941].

Nihon Bunpô Kôgohen (Gramática Japonesa - Série Língua Falada). Tóquio: Iwanami Zensho, 1978 [1950].

YAMADA, Yoshio. Nihon Bunpôgaku Gairon (Considerações Gerais sobre a Teoria da Gramática Japonesa). Tóquio: Hôbunkan, 1936.

Hôbunkan, 1970 [1908].

Nihon Bunpôron (Teoria Gramatical Japonesa). Tóquio:

Nihon Kôgohô Kôgi (Curso de Língua Moderna Japonesa). Tóquio: Hôbunkan, 1970b [1922].

Hôbunkan, 1971[1922].

Nihon Bunpôkôgi (Curso de Gramática Japonesa). Tóquio:

\section{Dicionários}

Gendai Porutogarugo Jiten (Dicionário do Português Contemporâneo). Tóquio: Hakusuisha, 1996.

KOKUGOGAKKAI. Kokugogaku Daijiten. (Grande Dicionário de Estudos Vernaculares). Tóquio: Tokyodô, 1980.

MELHORAMENTOS; ALIANÇA CULTURAL BRASIL-JAPÃO. Michaelis: Dicionário Prático Português-Japonês. São Paulo: 2000. 